\title{
Phenolic Content in Triticum Aestivum: A Review
}

\author{
P. S. Sutar-kapashikar, T. R. Gawali, S. R. Koli, A. S. Khot, S. P. Dehankar, Dr. P. D. Patil
}

\begin{abstract}
Young grass of Triticum aestivum is also called as wheat grass. Wheat grass is one of the important crop that provides nutrients to human body. This wheat grass is also called as "Green blood". It contains minerals, amino acids, vitamins and high content of chlorophyll. Wheat grass contains different phytochemicals such as alkaloid, flavonoid, phenol, tannin, glycosides etc. This review based on study of phenolic content in wheat grass extract by qualitative and quantitative analysis. The extraction is done by using two methods and with help of methanol solvent. This review also includes study of comparison of two methods in order to know best efficient method.
\end{abstract}

Index Terms- Green blood, Methanol, Phenol, Phytochemicals, Triticum aestivum, Wheat grass

\section{INTRODUCTION}

Wheat grass had history of over 5000 years from ancient Egypt. It is found that ancient Egyptians noticed that wheat grass is effective against some diseases. The experiments carried out by Charles Schnabel; an agricultural chemist leads to consumption of wheat grass in western world in 1930s. Schnabel added wheat grass powder in diet of his hens $\&$ he found that hens are healthy as well as they were giving double eggs. This experiment helps to increase the use of wheat grass [1]. Wheat grass (Triticum aestivum) belongs to the class of poaceae family that includes various grasses such as wheat grass [2]. Wheat grass is also called as "Green blood". Wheat is second most essential crop in India after rice crop. Wheat grass is earlier grass of wheat which is obtained at eighth or ninth day after cultivation. It is easy to cultivate, it does not require special conditions to be maintained and even does not require much care. Wheat grass contains vitamins $\mathrm{A}, \mathrm{C}$ and complex vitamins B along with calcium, phosphorous, sodium in small quantity. It also contains amino acids that are necessary for functioning and maintaining cell tissues of body [3].

Now a day, wheat grass is available as supplement food in the form of juice, powder and tablets. Wheat grass along with whey and maltodextrin is used for manufacturing of tablets [4]. The fresh wheat grass juice is used in "Green blood

P. S. Sutar-kapashikar, Chemical Technology, Department Of Technology, Shivaji University, Kolhapur, Maharashtra, India

T. R. Gawali, Chemical Technology, Department Of Technology, Shivaji University, Kolhapur, Maharashtra, India

S. R. Koli, Chemical Technology, Department Of Technology, Shivaji University, Kolhapur, Maharashtra, India

A. S. Khot, Chemical Technology, Department Of Technology, Shivaji University, Kolhapur, Maharashtra, India

S. P. Dehankar, Chemical Technology, Department Of Technology, Shivaji University, Kolhapur, Maharashtra, India

Dr. P. D. Patil, Chemical Technology, Department Of Technology, Shivaji University, Kolhapur, Maharashtra, India therapy". This therapy helps to cure various diseases with the help of fresh wheat grass juice [1]. As juice can't be preserved for longer time, it is converted into powder form that acts as functional food powder.

Wheat grass is used to treat common cold, fever, coughs, infection etc. It is used for production of hemoglobin, purifies blood, and removes toxic materials from body [13]. Wheat grass powder is used to treat Alzheimer's disease in Wistar rats [6]. Wheat grass extract is also used to treat breast cancer cell line because of its antioxidant activity [7].

Phenolic compounds are secondary metabolites produced in plant. Phenolic compound is act as antioxidant. These phenolic compounds are helps in treatment of diabetes, cardiovascular, inflammatory diseases. Phenolic compounds are found in both fruits and vegetables. Cocoa, potato, yam, tomato broccoli, as well as cereals are rich source of phenolic content [5].

Most of current researchers concentrate on extraction of wheat grass in order to know phytochemical constituents of it and to make best use of it in order to treat various diseases as it has multiple applications in medicinal field. Along with this it also used to synthesis of silver nanoparticles which still in the study [8].

This review study includes two methods for extraction of wheat grass such as solvent extraction by using soxhlet apparatus and mortar and pestle of wheat grass. Solvent extraction is carried by using soxhlet apparatus along with different solvents and in mortar and pestle of wheat grass wheat grass paste is formed and it is added with solvent then the solution is incubated overnight and extract is obtained which is further used for qualitative and quantitative analysis of phenolic content.

\section{MATERIALS AND METHODS}

\section{Cultivation of Triticum aestivum}

Wheat grass is easy to cultivate. It does not require much care. The suitable conditions for wheat grass production are temperature of $21 / 18{ }^{\circ} \mathrm{C}$ and relative humidity of 40 to $46 \%$ [9]. The unpolished wheat grains are spread on soil and it is allowed to grow with regular sprinkling of water. The grass which is obtained on eighth or ninth is taken for experiment.

\section{A. Extraction Using Soxhlet Apparatus}

M. Suriyayavathana, et al. [12] used the solvent extraction method in which cultivated grass of Triticum aestivum is taken and chopped. Then it is dried and milled to give fine powder. This powder is used for further study. In this method extract of wheat grass is used for extraction. Wheat grass powder is subjected to soxhlet apparatus and solvent methanol was used for extraction of wheat grass component (Phenol content). Once the extract is obtained solvent is recovered and extract is used for further study. 


\section{Qualitative screening}

Phenolics: $0.2 \mathrm{ml}$ of extract has taken. 1-2 drops of ferric chloride was added to the extract. After some time green color solution was obtained which indicates the presence of phenolics in extract.

\section{Quantitative screening}

Phenol: Folin - Ciocalteau reagent method proposed by Malic and Singh is used. In this test the extract is taken in the glass tubes then total $3 \mathrm{ml}$ volume is made. $0.5 \mathrm{ml}$ Folin Ciocalteau reagent in (1:1 with water) \& $2 \mathrm{ml} \mathrm{Na}_{2} \mathrm{CO}_{3}(20 \%)$ is added to the solution. Phenol reacts with phosphomolibdic acid in Folin -Ciocalteau reagent in alkaline medium, the complex redox reaction taken place. A blue colored complex, molybdenum blue is developed in the tube. This blue solution is warmed for $1 \mathrm{~min}$, and then cooled and absorbance was measured at $650 \mathrm{~nm}$ against reagent blank. Then known concentration of catechol at $650 \mathrm{~nm}$ is used to prepare standard curve. The total phenol content is calculated from standard curve [10].

\section{B. Extraction Using Mortar and Pestle}

Zendehbad et al [13] used the method of grinding. In this method wheat grass is cut and given to mortar and pestle to give homogenized paste. $5 \mathrm{gm}$ of this paste is mixed with 20 $\mathrm{ml}$ of solvent methanol. This solution is incubated overnight. Then solvent is removed and extract is obtained. This extract is concentrated in hot air oven at $55^{\circ} \mathrm{C}$. Then this concentrated extract is mixed with $10 \%$ dimethyl sulfoxide.

\section{Qualitative screening}

Phenolic: $0.2 \mathrm{ml}$ of extract has been taken in which 1-2 drops of ferric chloride $(0.5 \%)$ is added. Then the green color generation indicates presence of phenol.

\section{Quantitative screening}

Phenol: Folin Ciocalteu assay method is used for estimation of phenolic content. $0.5 \mathrm{ml}$ of extract is taken and it is incubated for $5 \mathrm{~min}$ after adding $0.5 \mathrm{ml}$ of Folin Ciocalteau reagent. Then $0.5 \mathrm{ml}$ sodium carbonate is added and solution is incubated for 2 hours. Then blue color is obtained. Then the absorbance of solution is measured at 765 nm.

\section{COMPARISON OF RESUlT}

The result of qualitative and quantitative analysis of phenolic content of Triticum aestivum for two different methods such by using soxhlet apparatus and by using mortar and pestle is shown in following table.

\section{CONCLUSION}

Wheat grass serves as both food supplement as well as medicinal component for various diseases. The presence of phenol compound helps to reduce effects of diseases such as cardiovascular, inflammatory, cancers. The antioxidant activity of wheat grass is due to presence of phenol in wheat grass extract. The quantity of phenol in solvent extraction is $0.50 \mathrm{mg} / \mathrm{gm}$ and in extraction by grinding using mortar and pestle it is found to be $0.04042 \mathrm{mg} / \mathrm{ml}$.

\section{REFERENCES}

[1] Neethu S. Kumar, Megha Murali, Anju M.Nair, Arun S. Nair, Green Blood Therapy of Wheat Grass - Nature's Finest Medicine- A Literature Review; IOSR Journal of Pharmacy and Biological Sciences, 2016, 11(2), pp 57-64

[2] Satyavati Rana, Jaspreet Kaur Kamboj and Vandana Gandhi., Living life the natural way-Wheatgrass and Health; Functional Foods in Health and Disease, 2011, 1(11), pp 444-456

[3] Mukthi Thammana, Seshamma Sreerangam and Sailaja Nambaaru. A Mini Review on Wheatgrass; Journal of Pharmacognosy and Phytochemistry, 2016, 4(3)

[4] Elif Akbas. Wheatgrass juice to wheat grass powder: encapsulation, physical \& chemical characterization; Journal of Functional Foods, 2017, vol. 28, pp 19-27

[5] Derong Lin, Mengshi Xiao, Jingjing Zhao, Zhuohao Li, Baoshan Xing, Xindan Li, Maozhu Kong, Liangyu Li, Qing Zhang, Yaowen Liu, Hong Chen, Wen Qin, Hejun Wu and Saiyan Chen, An Overview of Plant Phenolic Compounds and Their Importance in Human Nutrition and Management of Type 2 Diabetes; Molecules, 2016, 21, 1374, pp 1-19

[6] Veera Raghavulu Deepthi Rapaka, Nalini Mathala, Annapurna Akula., Effect of wheat grass powder on aluminum induced Alzheimer's disease in Wistar rats; Asian Pacific Journal of Tropical Medicine 2014, 7(1), pp 278- 281

[7] Simran Tondon, Amrita Arora, Sonali Singh, Jitender Monga and Shagun Aror. Antioxidant Profiling of Triticum aestivum (wheatgrass) and its Antiproliferative Activity In MCF-7 Breast Cancer Cell Line; Journal of Pharmacy Research, 2011, 4(12), pp 246-250

[8] Nandedkar Pushpa H and Khandare Sopan A. Synthesis of silver nanoparticles from wheatgrass extract and its biological applications; International Journal of Chemical Studies, 2018, 6(3), pp 113-116

[9] Singhal Ashish, Kumari Shilpa, Raghvendra Raghav Singh, Kumar Sanjay and Rajendran, N. Wheatgrass: An Alternative Household Nutritional Food Security; International Research Journal of Pharmacy, 2012, 3(7), pp 246-250

[10] Kavita S. Mundhe, Asha A. Kale, Sucheta A. Gaikwad, Nirmala R.Deshpande, Rajashree V. Kashalkar. Evaluation of phenol, flavonoid contents and antioxidents activity of Polyalthia longifolia; Journal of Chemical and Pharmaceutical Research, 2011, 3 (1), pp 764-769

[11] Panwar N.Wheetgrass (Triticum aestivum); A Super Herb Research and Reviews;Journal of Pharmaceutics and Nanotechnology,2015, 3(1)

[12] M. Suriyavathana, I Roopavathi, Vinu vijayan. Phytochemical Characterization of Triticum Aestivum (Wheat Grass); Journal of Pharmacognosy and Phytochemistry, 2016; 5(1), pp 283-286

[13] Seyed Hossein Zendehbad, Mohammad Javad Mehran Seyed, Flavonoids and Phenolic content in Wheat Grass Plant (Triticum aestivum); Asian Journal of Pharmaceutical and Clinical Research, 2014, 7(4), pp 184-187
Table 1: Phenolic content in Triticum Aestivum

\begin{tabular}{|c|l|c|c|}
\hline $\begin{array}{c}\text { Sr. } \\
\text { No. }\end{array}$ & $\begin{array}{c}\text { Metho } \\
\text { ds }\end{array}$ & $\begin{array}{l}\text { Qualitative } \\
\text { Analysis }\end{array}$ & $\begin{array}{l}\text { Quantitative } \\
\text { Analysis }\end{array}$ \\
\hline 1 & $\begin{array}{l}\text { Soxhlet } \\
\text { apparatus }\end{array}$ & Present & $0.50 \mathrm{mg} / \mathrm{gm}$ \\
\hline 2 & $\begin{array}{l}\text { Mortar } \\
\text { and pestle }\end{array}$ & Present & $0.4042 \mathrm{mg} / \mathrm{ml}$ \\
\hline
\end{tabular}

